\title{
Awareness On Healthy Dietary Habits Among Prospective Teachers In Tirunelveli District
}

\author{
Dr.M.Maria Saroja ${ }^{\text {a }}$, E.Michael Jeya Priya ${ }^{\text {b }}$ \\ ${ }^{a}$ Principal i/c, Research Director \& Associate Professor of Biological Science, Former Controller of Examinations, St. Ignatius \\ College of Education (Autonomous), Palayamkottai. \\ ${ }^{\mathrm{b}}$ Assistant Professor of Biological Science, St. Ignatius College of Education (Autonomous), Palayamkottai
}

Article History: Received: 10 November 2020; Revised 12 January 2021 Accepted: 27 January 2021; Published online: 5 April 2021

\begin{abstract}
Unhealthy dietary habits are related to diabetes, cardiovascular disease, and increased obesity risk over the past decades. It's mainly due to the dietary factors and lack of physical activities among students. Unhealthy food eating habits and lack of food knowledge and health products leads to severe health problems in the young generation. They prefer food based on their taste, look especially in their psychological point of view not based on their healthy aspects. They often prefer outside foods especially from hotels and local food shops this may affect their immunity and increase the risk of various disease. The main objective of the present study was to find out the awareness on healthy dietary habits among prospective teachers in Tirunelveli district. Survey method was adopted by the investigators to conduct this study. The sample consists of 250 prospective teachers in Tirunelveli District. Healthy Dietary Habits Awareness Scale was developed by Maria Saroja, M and Michael Jeya Priya, E (2020) has been used for collecting data. Mean, SD, ' $t$ '- test and $\chi 2$ was used for analysis the data. The investigators found that i) there is significant difference between rural and urban, nuclear and joint family prospective teachers in their awareness on the healthy dietary habits (ii) there is no significant difference between girls and co-education prospective teachers in their awareness on the healthy dietary habits (iii) there is no significant association between prospective teachers in their awareness on the healthy dietary habits with reference to the father's educational qualification and mothers educational qualification.
\end{abstract}

Keywords: Healthy dietary habits, cardiovascular disease, diabetes, obesity

\section{Introduction}

Dietary habits are the food choices preferred by persons in their daily life. A healthy dietary habit helps an individual to stay fit and well throughout his life. Healthy diet includes fruits, vegetables, cereals and water, low fat dairy products, etc. (Sultana.N.2017).Dietary habits are the habitual decisions an individual or culture makes when choosing what foods to eat. The word diet often implies the use of specific intake of nutrition for health or weight-management reasons. Although humans are omnivores, each culture and each person holds some food preferences or some food taboos. This may be due to personal tastes or ethical reasons. Individual dietary choices may be more or less healthy. Dietary habits and choices play a significant role in the quality of life, health and longevity ( Rayar \& Davies 2015) Good nutrition is an important part of leading a healthy lifestyle. Combined with physical activity, diet can help to reach and maintain a healthy weight, reduce risk of chronic diseases (like heart disease and cancer), and promote overall health.(Ngozi.M. et al.,2017) These include heart disease, hypertension (high blood pressure), type 2 diabetes, osteoporosis, and certain types of cancer. By making smart food choices, can help protect ourselves from these health problems. The risk factors for adult chronic diseases, like hypertension and type 2 diabetes, are increasingly seen in younger ages, often a result of unhealthy eating habits and increased weight gain. Dietary habits established in childhood often carry into adulthood, so teaching children how to eat healthy at a young age will help them stay healthy throughout their life. (Adonova.A.2014) The link between good nutrition and healthy weight, reduced chronic disease risk, and overall health is too important to ignore. Apart from the lack of nutrients, the outside sourced breakfast is also bound to contain substandard ingredients such as poor quality cooking oil and expired ingredients. Awareness about proper nutrition and healthy dietary habits can make a difference in the society. So it's a need of an hour to increase healthy dietary awareness among prospective teachers.

\section{Significance Of The Study}

Prospective teachers are at risk for making poor dietary choices that can cause significant health problems. They are unaware of the nutritional requirements to maintain a healthy body weight, they make poor nutritional decision, which can cause poor weight management and health problems. Prospective teachers select food according to convenience, taste, time, and price rather than nutritional values. Poor nutrition due to unhealthy 
eating habits may lead to delayed puberty, nutrient deficiencies and dehydration, menstrual irregularities, poor bone health, increased risk of injuries, poor academic performance and increased risk of eating disorders. The student teachers who are nutrition under eaters may be affected by anorexia or bulimia. Prospective teachers who do not eat breakfast, or eat an insufficient breakfast, are more likely to have behavioral, emotional and academic problems at college. Prospective teachers who consume unhealthy foods can have trouble concentrating, become easily fatigued, listless or irritable and are likely to face difficulties in learning, which can lead to behavioral and social problems. Teaching prospective teachers about the importance of good nutrition lay the foundation for a healthier and more fulfilling life. Poor eating habits and nutritional knowledge deficits may affect health of the youngsters. Healthy eating habits may help to eliminate carbonated soft drinks and unhealthy junk foods from their routine diets. The high intake of sugar rich and white flour foods such as cookies and cakes will increase the risk of obesity among college students. The significance of this research is to enlighten the prospective teachers about the importance of healthy dietary habits.

\section{Review Of Related Studies}

Maria Saroja, M.,\& Michael Jeya Priya,E (2020) conducted study on the detrimental effects of soft drinks consumption among college students in Tirunelveli District. In their study they find out that there is a significant difference in the gender and type of family in their awareness on the detrimental effects of soft drinks consumption among college students. Abraham, S., Noriega, B.R., \& Shin, J.Y (2018) conducted a study on college students eating habits and knowledge of nutritional requirements. Quantitative, cross sectional study with descriptive study was used in this study. In their study they showed that students have a fair knowledge of nutritional requirements for health. Maria Saroja, M., \& Michael Jeya Priya, E (2018) conducted a study on awareness on ill effects of junk food among college students in Tirunelveli District. In this study they revealed that, there was a significant difference among higher secondary students in their awareness about the ill effects of Junk food. Salama,A.A.,\& Ismael,N.M(2018) conducted study on the nutritional awareness and dietary practices of college-aged students for developing an effective nutritional educational plan. They conducted cross sectional study among 165 first years under graduate students. The findings of their study revealed that students have poor nutritional knowledge about the macro and micro nutrients. Baseer, Revethi, Ayesha, Ramesh, Hiremath.,\& Sreekantha(2015) conducted a cross sectional study at preuniversity college students in Raichur, India. In their findings they showed that unhealthy dietary habits are prevalent among adolescents.

\section{Objectives Of The Study}

- $\quad$ To find out the level of awareness on healthy dietary habits among prospective teachers.

- $\quad$ To find out whether there is any significance difference between prospective teachers in their awareness towards the healthy dietary habits with reference to the following background variables (i)Gender (ii)Locality of residence (iii)Nature of college (iv)Type of family (v) Medium of Instruction

- $\quad$ To find out whether there is any significant difference among prospective teachers in their awareness on healthy dietary habits with reference to father's and mother's educational qualification.

\section{Hypotheses Of The Study}

- Awareness on healthy dietary habits among prospective teachers are moderate.

- There is no significant difference between prospective teachers in their awareness on healthy dietary habits with reference to the following background variables.

(i)Gender (ii)Locality of residence (iii)Nature of college (iv)Type of family (v)Medium of Instruction

- There is no significant difference among prospective teachers in their healthy dietary habits with reference to father's and mother's educational qualification

\section{Population And Sample}

The population includes prospective teachers of Tirunelveli District. The investigators used simple random sampling technique and randomly selected 250 prospective teachers in Tirunelveli District.

\subsection{Statistical Techniques Used in the Present Study}

Healthy Dietary Habits Awareness Scale was developed and validated by Maria Saroja .M and Michael Jeya Priya. E (2018). Mean, Standard deviation, ' $t$ ' test and $\chi^{2}$ were used to analyze the data.

\subsection{Data Analysis and Interpretation}

Table.1. showing the percentage level of the awareness on the dietary habits among prospective teachers in Tirunelveli District. 


\begin{tabular}{|l|r|c|c|c|c|c|}
\hline \multirow{2}{*}{$\begin{array}{c}\text { Awareness } \\
\text { on the dietary } \\
\text { habits }\end{array}$} & \multicolumn{2}{|c|}{ Low } & \multicolumn{2}{c|}{ Average } & \multicolumn{2}{c|}{ High } \\
\cline { 2 - 7 } & $\mathrm{N}$ & $\%$ & $\mathrm{~N}$ & $\%$ & $\mathrm{~N}$ & $\%$ \\
\cline { 2 - 7 } & 57 & 22.80 & 141 & 56.40 & 52 & 20.80 \\
\hline
\end{tabular}

Figure.1 showing the percentage level of the awareness on healthy dietary habits among prospective teachers in Tirunelveli district.
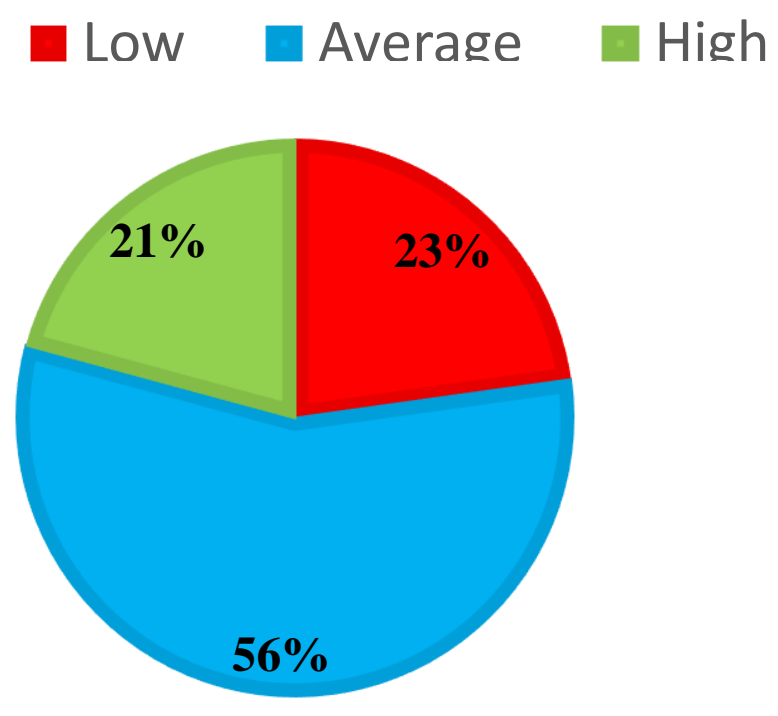

\section{Interpretation of table-1.}

It is revealed from the above table that among the prospective teachers $22.80 \%$ have low, $56.40 \%$ have average and $20.80 \%$ have high level of awareness on healthy dietary habits .

Table.2. Difference between male and female prospective teachers in their awareness on healthy dietary habits.

\begin{tabular}{|c|c|c|c|c|c|c|c|}
\hline Variable & Categories & $\mathbf{N}$ & Mean & SD & $\begin{array}{c}\text { Calculated } \\
\text { 't' } \text { ' Value }\end{array}$ & $\begin{array}{c}\text { Table } \\
\text { Value }\end{array}$ & Remark \\
\hline \multirow{2}{*}{ Gender } & Male & 133 & 61.71 & 7.41 & 0.80 & 1.96 & NS \\
\cline { 2 - 7 } & Female & 117 & 61.03 & 5.89 & & & \\
\hline
\end{tabular}

Interpretation of table-2.

There is no significant difference between male and female prospective teachers in their awareness on healthy dietary habits.

Figure.2.Showing the awareness on healthy dietary habits among prospective teachers in Tirunelveli District 


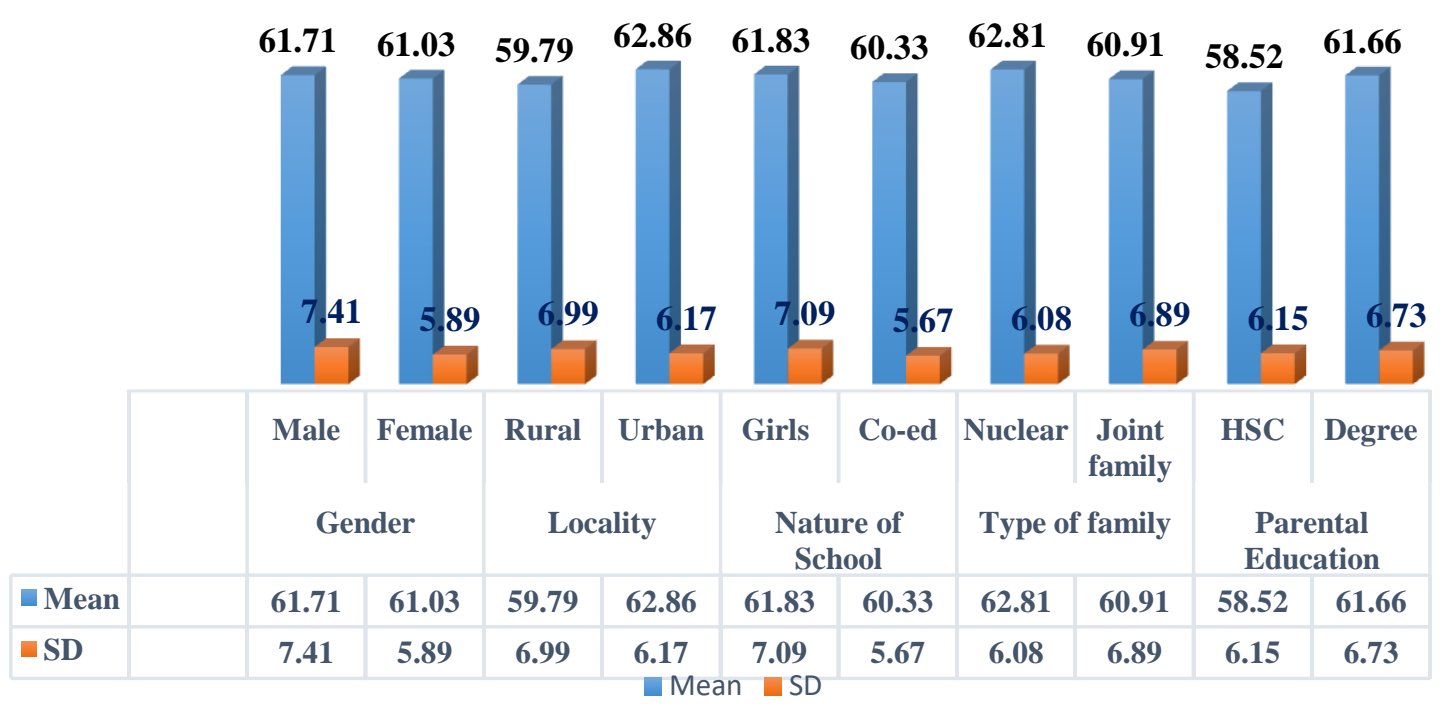

Table.3. Difference between rural and urban prospective teachers in their awareness on healthy dietary habits.

\begin{tabular}{|l|l|l|l|l|l|l|l|}
\hline Variable & Categories & $\mathbf{N}$ & Mean & SD & $\begin{array}{l}\text { Calculated } \\
\text { 't' Value }\end{array}$ & $\begin{array}{l}\text { Table } \\
\text { Value }\end{array}$ & Remark \\
\cline { 1 - 6 } Locality & Rural & 118 & 59.79 & 6.99 & 3.62 & 1.96 & S \\
\cline { 2 - 5 } & Urban & 132 & 62.86 & 6.17 & & \\
\hline
\end{tabular}

Interpretation of table-3.

There is significant difference between rural and urban prospective teachers in their awareness on healthy dietary habits.

In the present study, the mean of healthy dietary habits scale value of urban prospective teachers (62.86) is greater than that of rural prospective teachers (59.79). This may be due to the fact that, urban prospective teachers involve themselves in nutrition education programs related to improving dietary habits. They organize various events related to dietary programs such as food festival, awareness campaign, and talk show on healthy diets. Their awareness towards the ill effects of junk food eating habits and soft drink consumption has been increased now- a- days. The college professors and college management insist the importance of fruits, vegetables, cereals for their healthy growth. They are given awareness about the healthy eating habits.

The urban students are well aware of dietary plans and food chart which will make them to stay healthy compare to rural students. They participate in various nutritional seminars, counselling and workshop on a regular basis to enhance their awareness and knowledge of healthy eating habits. The food guide pyramid with suitable graphics and pictures are displayed on college campus, canteen walls and corridors to enhance the healthy eating habits. This result contradicted with the study conducted by Bargiota.A.,et al.,2013. In their studies they showed family factors, peers, and family affects the food choice of Greek rural adolescents.

Table.4. Difference between girls and co-education prospective teachers in their awareness on healthy dietary habits.

\begin{tabular}{|l|l|l|l|l|l|l|l|}
\hline Variable & Categories & $\mathbf{N}$ & Mean & SD & $\begin{array}{l}\text { Calculated 't' } \\
\text { Value }\end{array}$ & $\begin{array}{l}\text { Table } \\
\text { Value }\end{array}$ & Remark \\
\hline \multirow{2}{*}{ Nature of college } & Girls & 177 & 61.83 & 7.09 & 1.76 & 1.96 & NS \\
\cline { 2 - 8 } & Co-ed & 73 & 60.33 & 5.67 & & & \\
\hline
\end{tabular}

Interpretation of table-4.

There is no significant difference between girls and co-education prospective teachers in their awareness on healthy dietary habits. 
Table.5. Difference between nuclear and joint family prospective teachers in their awareness on healthy dietary habits.

\begin{tabular}{|l|l|l|l|l|l|l|l|}
\hline Variable & Categories & $\mathbf{N}$ & Mean & SD & $\begin{array}{l}\text { Calculated 't' } \\
\text { Value }\end{array}$ & $\begin{array}{l}\text { Table } \\
\text { Value }\end{array}$ & Remark \\
\hline \multirow{2}{*}{ Type of family } & Nuclear & 63 & 60.91 & 6.89 & 2.07 & & \\
\cline { 2 - 8 } & Joint family & 187 & 62.81 & 6.08 & & 1.96 & $\mathrm{~S}$ \\
\hline
\end{tabular}

\section{Interpretation of table-5.}

There is significant difference between the Nuclear and Joint family prospective teachers in their awareness on healthy dietary habits.

In the present study, the mean of healthy dietary habits scale value of joint prospective teachers (62.81) is greater than that of nuclear family prospective teachers (60.91). This may due to the fact that, joint family influence more in the healthy eating habits family members in the joint family serve as a role models in influencing children's regular meal and snack time every day.

Joint family members create positive experience about traditional food items which help children to develop good healthy diets. Grandparents were the primary caretakers of their grandchildren from their birth. They play an important role in planning daily meals for their family members. They are aware of the adiposity rebound in childhood is critical for the development of adult obesity so they tend to take care of their grandchildren with prime health care. They urge their grandchildren's to eat more meals at served meals and express love and caring through food. This result support the study conducted by jingxiong.J. et al.,2006. In their studies they showed that grandparents were dominant in shaping children's eating behavior. They provide a potential frame work for developing a healthy dietary behavior in young children.

Table.6. Association between father's educational qualifications of prospective teachers in their awareness on healthy dietary habits.

\begin{tabular}{|c|c|c|c|c|c|c|c|c|c|}
\hline Variable & $\begin{array}{c}\text { Catego } \\
\text { ries }\end{array}$ & $\begin{array}{c}\text { Mea } \\
\mathbf{n}\end{array}$ & Low & $\begin{array}{c}\text { Avera } \\
\text { ge }\end{array}$ & High & df & $\begin{array}{c}\text { Calculate } \\
\text { d ' } \chi^{2} \text {, } \\
\text { Value }\end{array}$ & $\begin{array}{c}\text { Tabl } \\
\text { e } \\
\text { Valu } \\
\text { e }\end{array}$ & Remark \\
\hline \multirow{3}{*}{$\begin{array}{l}\text { Father's } \\
\text { Educational } \\
\text { qualification }\end{array}$} & School & $\begin{array}{c}61.6 \\
6\end{array}$ & $26(24)$ & $58(59)$ & $21(22)$ & \multirow[t]{3}{*}{4} & \multirow[t]{3}{*}{7.60} & \multirow[t]{3}{*}{9.49} & \multirow[t]{3}{*}{ NS } \\
\hline & $\begin{array}{l}\text { UG } \\
\text { level }\end{array}$ & $\begin{array}{c}62.3 \\
6\end{array}$ & $18(13)$ & $25(31)$ & $12(11)$ & & & & \\
\hline & $\begin{array}{l}\mathrm{PG} \\
\text { level }\end{array}$ & $\begin{array}{c}60.4 \\
9 \\
\end{array}$ & $13(21)$ & $58(51)$ & 19(19) & & & & \\
\hline
\end{tabular}

(At $5 \%$ level of significance of $4 \mathrm{df}$, the table value of $\chi^{2}$ is 9.49)

\section{Interpretation of table-6.}

It is inferred from the above table that there is no significant association between the awareness on healthy dietary habits of prospective teachers and their father's educational qualification.

Table.7. Association between mother's educational qualifications of prospective teachers in their awareness on healthy dietary habits.

\begin{tabular}{|c|c|c|c|c|c|c|c|c|c|}
\hline Variable & $\begin{array}{c}\text { Categorie } \\
\mathrm{s}\end{array}$ & $\begin{array}{c}\text { Mea } \\
\mathbf{n}\end{array}$ & Low & $\begin{array}{c}\text { Averag } \\
\text { e }\end{array}$ & High & df & $\begin{array}{c}\text { Calculate } \\
\text { d ' } \chi^{2} \text { ' } \\
\text { Value }\end{array}$ & $\begin{array}{c}\text { Table } \\
\text { Valu } \\
\text { e }\end{array}$ & $\underset{k}{\text { Remar }}$ \\
\hline \multirow{3}{*}{$\begin{array}{l}\text { Mother's } \\
\text { Education } \\
\text { al } \\
\text { qualificati } \\
\text { on }\end{array}$} & School & 61.86 & $42(37)$ & $88(92)$ & $33(34)$ & \multirow{3}{*}{4} & \multirow{3}{*}{2.57} & \multirow{3}{*}{9.49} & \multirow{3}{*}{$S$} \\
\hline & UG level & 60.71 & $8(12)$ & $32(29)$ & 11(11) & & & & \\
\hline & PG level & 60.25 & $7(8)$ & $21(20)$ & $8(7)$ & & & & \\
\hline
\end{tabular}

(At $5 \%$ level of significance of $4 \mathrm{df}$, the table value of $\chi^{2}$ is 9.49 


\section{Interpretation of table-6.}

It is inferred from the above table that there is no significant association between the awareness on healthy dietary habits of prospective teachers and their mother's educational qualification.

\section{Recommendations}

- Nutritional report cards could be practiced in the college campus; this will help them continue the same in their school teaching.

- Constant medical checkups and BMI awareness can be implemented on the college campus to know about the students' health status.

- $\quad$ Diet menu should be followed in the hostel.

- $\quad$ Food hours could be expanded to allow more time for students to eat meals without "off-hour" meal restrictions

- $\quad$ Food Club would increase food culture on campus and stand as an additional resource for students.

- Traditional Food festivals will help them to understand the different varieties of food grains and their nutritional values.

- $\quad$ Junk food-free campus can be accomplished in the college.

- $\quad$ Eating together or a family meal can be practiced in the family will improve dietary intake among college students.

\section{Conclusion}

The college environment plays an important role in shaping sustaining healthy eating habits among youngsters. Since prospective teachers are the upcoming teachers who will be the role model for their school children they can promote valuable nutritional information through their own daily food practices. College campus, canteen and college dining halls plays a crucial role in guiding dietary eating environments among students. Display of information about healthy diet in the college notice boards provides knowledge to a large number of socio economic and cultural backgrounds. The continuous healthy eating habits effective policies and managerial strategies followed inside the college campus helps to fight malnutrition such as obesity, anorexia, and microdeficiency. Proper diet and physical activity will lead to maintain healthy weight and lifestyle among Prospective teachers. Diets rich in high fibre reduce the risk of obesity and various health problems. Healthy dietary habits help to maintain good physique, relieve stress, stroke prevention, improve learning, mental health, build better mood, and self esteem. Parents also influence more in their children's food preference through their verbal dietary comments and restrictions employed in consuming un healthy food items. Consuming fruits and vegetables is one of the important healthy behaviors to achieve one's optimal physical function. Social media plays a vital role in encouraging healthy eating behaviors through various traditional cooking programs, advertisements, talk shows, debates, panel discussion etc. Parents continuous monitoring of their wards is very important in maintaining good health. Thus constant practice, knowledge and monitoring of the health practice of the college students will create a healthy nation.

\section{References}

Abraham, S, Brooke R. Noriega, Ju Young Shin (2018). College students eating habits and knowledge of nutritional requirements. Journal of Nutrition and Human Health, 2(1), 13-17.

Andonova, A. The nutritional habits of female students aged 18 to 25 . Trakia Journal of Sciences, 16(1), 235240.

Bargiota, A, et al (2013). Eating habits and factors affecting food choice of adolescents living in rural areas. Hormones, 12(2), 246-253.

Baseer,Revathi, Ayesha,S.,(2015) Dietary habits and life style among Pre-universtiy college students in Raichur, India. International Journal of Research in Health Sciences, 2(3), 407-411.

Das,B, Evans,E.(2014). Understanding weight management perceptions in first-year college studnets using the health belief model, J Am Coll Health, 62, 488-97.

Jingxiong, et al (2006). Influence of grandparents on eating behaviors of young children in Chinese threegeneration families. Science Direct, 48(3),377-383,

Retrieved from https://www.sciencedirect.com/science/article/pii/S0195666306006325.

Saroja,M.M \& Priya,E.M.J.(2020). Awareness on detrimental effects of soft drinks consumption among college students in Tirunelveli district. Test Engineering and Management, 83, 7823-7829. 
Saroja,M.M \& Priya,E.M.J.(2018).Awareness on ill effects of junk food among higher secondary students in Tirunelveli district. International Research Journal of Mnaagement Sociology and Humanity,8(10), 79-87.

Ngozi, E., (2017). Alcohol consumption and awareness of its effects on health among secondary school students in Nigeria, 96(48), E8960

Rayar, O \& Davies, J., (1996). Cross-culture aspects of eating disorders in Asian girls. Nutrition \& Food Science, 96(4), 19-22.

Salama,A.A \& Ismael,N.M.(2018). Assessing Nutritional Awareness and Dietary Practies of College-aged students for developing an Effective Educational Plan. Canad J Clin Nutr, 6(2), 22-42.

Sultana, N. (2017). Nutritional Awareness among the Parents of Primary School going Children. Saudi J. Humanities Soc. Sci., 2(8), 708-725

https://www.researchgate.net/publication/322925099_College_Students'_Eating_Habits_and_Knowledge_of_Nu tritional_Requirements

https://www.researchgate.net/publication/6632641_Influence_of_Grandparents_on_Eating_Behaviors_of_Young _Children_in_Chinese_Three-generation_Families

Kaur S, Kapil U, Singh P. Pattern of chronic diseases amongst adolescent obese children in developing countries. Curr Sci. 2005; 88:1052-6.

Khadilkar VV, Khadilkar AV. Prevalence of obesity in affluent school boys in Pune. Indian Pediatr. 2004; 41:857-8. [PubMed]

Kapil U, Singh P, Pathak P, Dwivedi SN, Bhasin S. Prevalence of obesity amongst affluent adolescent school children in Delhi. Indian Pediatr. 2002; 39:449-52 